\title{
Efficient separation of acetylene and carbon dioxide in a decorated zeolite
}

\author{
Shanshan Liu, Xue Han, Yuchao Chai, Guangjun Wu, Weiyao Li, \\ Jiangnan Li, Ivan da-Silva, Pascal Manuel, Yongqiang Cheng, Luke \\ L Daemen, Anibal J Ramirez-Cuesta, Wei Shi, Naijia Guan, Sihai \\ Yang and Landong Li
}

\section{Published version information}

This is the peer reviewed version of the following article:

Citation: S Liu et al. 'Efficient separation of acetylene and carbon dioxide in a decorated zeolite.' Angew Chem, vol. 60, no. 12 (2020): 6526-6532.

DOI: 10.1002 /ange. 202014680

Which has been published in final form at DOI above. This article may be used for non-commercial purposes in accordance with Wiley-VCH terms and conditions for self-archiving.

Please cite only the published version using the reference above. This is the citation assigned by the publisher at the time of issuing the AAM. Please check the publisher's website for any updates. 


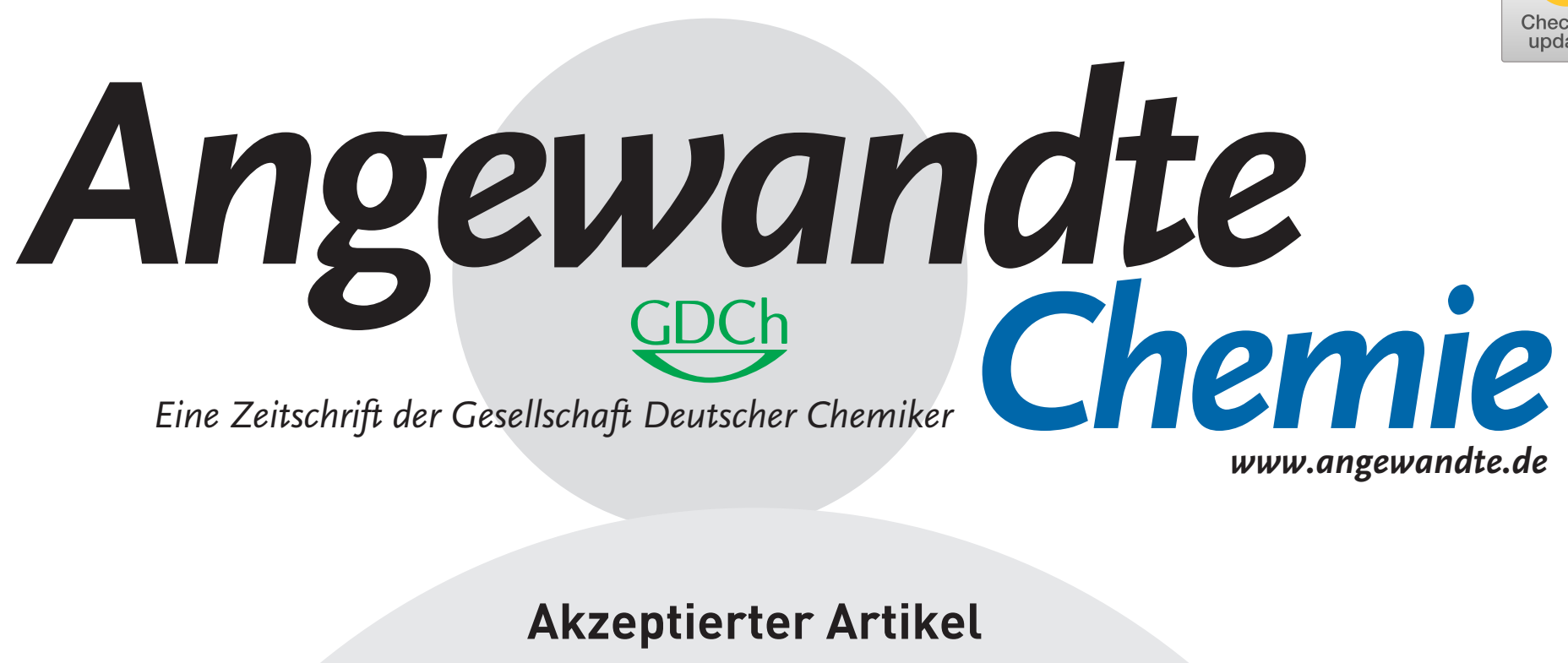

Titel: Efficient separation of acetylene and carbon dioxide in a decorated zeolite

Autoren: Shanshan Liu, Xue Han, Yuchao Chai, Guangjun Wu, Weiyao $\mathrm{Li}$, Jiangnan $\mathrm{Li}$, Ivan da-Silva, Pascal Manuel, Yongqiang Cheng, Luke L Daemen, Anibal J Ramirez-Cuesta, Wei Shi, Naijia Guan, Sihai Yang, and Landong Li

Dieser Beitrag wurde nach Begutachtung und Überarbeitung sofort als "akzeptierter Artikel" (Accepted Article; AA) publiziert und kann unter Angabe der unten stehenden Digitalobjekt-Identifizierungsnummer (DOI) zitiert werden. Die deutsche Übersetzung wird gemeinsam mit der endgültigen englischen Fassung erscheinen. Die endgültige englische Fassung (Version of Record) wird ehestmöglich nach dem Redigieren und einem Korrekturgang als Early-View-Beitrag erscheinen und kann sich naturgemäß von der AA-Fassung unterscheiden. Leser sollten daher die endgültige Fassung, sobald sie veröffentlicht ist, verwenden. Für die AA-Fassung trägt der Autor die alleinige Verantwortung.

Zitierweise: Angew. Chem. Int. Ed. 10.1002/anie.202014680

Link zur VoR: https://doi.org/10.1002/anie.202014680 


\title{
Efficient separation of acetylene and carbon dioxide in a decorated zeolite
}

\author{
Shanshan Liu, ${ }^{[a]}$ Xue Han, ${ }^{[b]}$ Yuchao Chai, ${ }^{[a]}$ Guangjun Wu, ${ }^{[a]}$ Weiyao Li,,${ }^{[b]}$ Jiangnan Li, ${ }^{[b]}$ Ivan da-Silva, ${ }^{[c]}$ \\ Pascal Manuel, ${ }^{[c]}$ Yongqiang Cheng, ${ }^{[d]}$ Luke L. Daemen, ${ }^{[d]}$ Anibal J. Ramirez-Cuesta, ${ }^{[d]}$ Wei Shi, ${ }^{[e]}$ Naijjia \\ Guan, ${ }^{[a]}$ Sihai Yang ${ }^{*[b]}$ and Landong $\mathrm{Li}^{*[a]}$
}

Shanshan Liu and Xue Han contributed equally to this work.

Dedicated to the $100^{\text {th }}$ anniversary of Chemistry at Nankai University

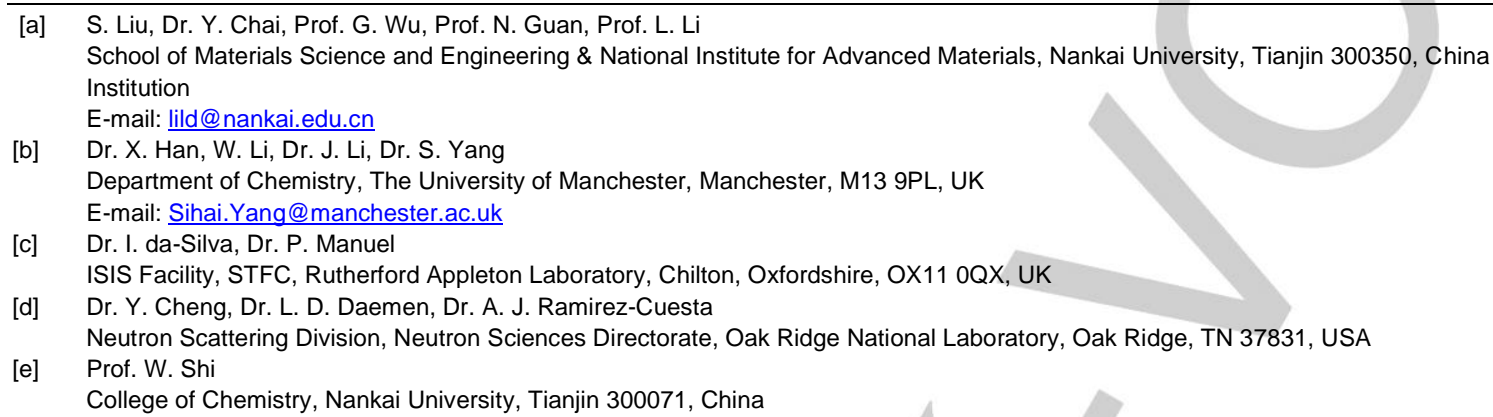

\begin{abstract}
The almost identical molecular sizes and volatilities of acetylene and carbon dioxide make their separation extremely challenging in industry. Here, we report the efficient separation of acetylene and carbon dioxide $(\mathrm{v} / \mathrm{v}=2 / 1$, which is relevant to that in the industrial cracking stream) in faujasite zeolites decorated with atomically-dispersed copper(II) sites under ambient conditions. In situ neutron powder diffraction and inelastic neutron scattering confirm that the confined copper(II) site displays chemo-selective yet reversible binding to acetylene, whereas adsorbed carbon dioxide molecules are stablished by weak host-guest supramolecular interactions with the framework oxygen centres, thus resulting in the efficient separation of these two gases under flow conditions. A designed adsorption-purging-desorption system based upon Cu@FAU is established for the recovery of high purity acetylene $(98-99 \%)$ from the mixture of acetylene and carbon dioxide, offering an unprecedented separation factor of 22.2 with an effective dynamic uptake of acetylene of $1.51 \mathrm{mmol} \mathrm{g}^{-1}$ at $298 \mathrm{~K}$.
\end{abstract}

\section{Introduction}

Acetylene $\left(\mathrm{C}_{2} \mathrm{H}_{2}\right)$ has a wide range of industrial applications, such as metal cutting and instrumental analysis, and more importantly, it is an essential building block for the manufacture of numerous materials and fine chemicals, such as synthetic fibres, rubber, acetic acid and benzene..$^{[1]} \mathrm{C}_{2} \mathrm{H}_{2}$ is mainly produced by petroleum cracking and partial combustion of methane, where carbon dioxide $\left(\mathrm{CO}_{2}\right)$ as byproduct can reach a concentration up to $\sim 50 \%$ of that of $\mathrm{C}_{2} \mathrm{H}_{2}$ in the gas stream, causing serious problems to the downstream application of $\mathrm{C}_{2} \mathrm{H}_{2}$. Therefore, the removal of $\mathrm{CO}_{2}$ from the $\mathrm{C}_{2} \mathrm{H}_{2}$ stream is of vital importance to obtain high-purity $\mathrm{C}_{2} \mathrm{H}_{2}$ for further applications. State-of-the-art techniques to separate $\mathrm{C}_{2} \mathrm{H}_{2}$ and $\mathrm{CO}_{2}$ are based upon extraction of $\mathrm{C}_{2} \mathrm{H}_{2}$ by organic solvents (e.g., dimethylformamide and acetone) and cryogenic distillation, which are among the most energy-intensive industrial separation processes with significant environmental impacts. ${ }^{[2]}$ The development of energy-efficient strategies for the separation of $\mathrm{C}_{2} \mathrm{H}_{2} / \mathrm{CO}_{2}$ remains an important and challenging line of research owing to their similar physical properties (Supporting Information, Table S1), for example the same molecular shape, almost identical sizes $\left(\mathrm{C}_{2} \mathrm{H}_{2}, 3.3 \times 3.3 \times 5.7 \AA^{3} ; \mathrm{CO}_{2}, 3.2 \times 3.3 \times 5.4 \AA^{3}\right)$ and very close boiling points $\left(\mathrm{C}_{2} \mathrm{H}_{2}, 189.3 \mathrm{~K} ; \mathrm{CO}_{2}, 194.7 \mathrm{~K}\right) .{ }^{[3]}$

Adsorptive separation based upon porous sorbents affords increasing promise for gas separation at (near) ambient conditions and is attracting much interest from both academia and industry. ${ }^{[4-7]}$ Various porous materials, such as activated carbons, $^{[8]}$ silica ${ }^{[9]}$ and metal-organic frameworks (MOFs), ${ }^{[3,10-19]}$ have been studied for the adsorptive separation of $\mathrm{C}_{2} \mathrm{H}_{2} / \mathrm{CO}_{2}$. MOFs attracted particular attention because of their abundant structural diversity and design flexibility. ${ }^{[20-24]}$ Zeolites, as conventional sorbent materials, ${ }^{[25,26]}$ are potentially superior to MOFs for gas separations at an industrial scale owing to their high hydrothermal stability, recyclability and low production cost. However, the separation of mixtures of $\mathrm{C}_{2} \mathrm{H}_{2} / \mathrm{CO}_{2}$ in zeolites has not been achieved to date because physisorption of $\mathrm{C}_{2} \mathrm{H}_{2}$ and $\mathrm{CO}_{2}$ within pristine zeolites often exhibit similar uptakes and adsorption profiles, leading to no apparent selectivity to afford any practical separation. ${ }^{[27]}$

We have recently developed a $\mathrm{Ni}(\mathrm{II})$-decorated zeolite material, which shows an excellent performance in the purification of lower olefins by efficient binding and removal of alkyne impurities. ${ }^{[28]}$ The introduced $\mathrm{Ni}(\mathrm{II})$ sites have enabled chemoselective and reversible binding to alkynes through the formation of metastable $\left[\mathrm{Ni}(\mathrm{II})(\text { alkyne })_{3}\right]$ complexes. This creates an exciting avenue to explore the application of decorated zeolites in challenging industrial separations. Here, we report, to the best of our knowledge, the first example of recovery of highpurity $\mathrm{C}_{2} \mathrm{H}_{2}$ via efficient separation of the mixture of $\mathrm{C}_{2} \mathrm{H}_{2} / \mathrm{CO}_{2}$ in decorated zeolites. By the incorporation of coordinatively unsaturated $\mathrm{Cu}(\mathrm{II})$ sites in FAU zeolites, Cu@FAU exhibits high dynamic adsorption capacity of $\mathrm{C}_{2} \mathrm{H}_{2}$ and excellent separation of the mixture of $\mathrm{C}_{2} \mathrm{H}_{2} / \mathrm{CO}_{2}$ at ambient conditions. The physisorbed $\mathrm{CO}_{2}$ molecules on Cu@FAU can be readily removed by purging 
at ambient temperature, while most bound $\mathrm{C}_{2} \mathrm{H}_{2}$ molecules are preserved. As a result, $\mathrm{C}_{2} \mathrm{H}_{2}$ with purity of $98-99 \%$ can be obtained by the regeneration of sorbents via conventional temperature-swing desorption. The underlying adsorption mechanisms of $\mathrm{C}_{2} \mathrm{H}_{2}$ and $\mathrm{CO}_{2}$ in $\mathrm{Cu} @ \mathrm{FAU}$ have been fully elucidated by in situ neutron powder diffraction (NPD) and inelastic neutron scattering (INS), which revealed an unusual geometry for bound $\mathrm{C}_{2} \mathrm{H}_{2}$ molecules on the $\mathrm{Cu}(\mathrm{II})$ sites. This study represents an appealing strategy of using decorated zeolites to enable facile production of high-purity $\mathrm{C}_{2} \mathrm{H}_{2}$ from the mixture of $\mathrm{C}_{2} \mathrm{H}_{2} / \mathrm{CO}_{2}$ through chemoselective adsorption of $\mathrm{C}_{2} \mathrm{H}_{2}$.

\section{Results and Discussion}

Synthesis and characterisation. M@FAU zeolites $[\mathrm{M}=\mathrm{Ni}(\mathrm{II})$, $\mathrm{Cu}(\mathrm{II})$ and $\mathrm{Zn}(\mathrm{II})]$ were synthesised via hydrothermal reactions with a bifunctional organic ligand $\{\mathrm{N}-[3-$ (trimethoxysilyl)propyl]ethylenediamine for the introduction of metal ions into the desired location within the zeolite matrix, which is difficult to access via post-synthetic ion-exchange. Coordinatively unsaturated cations at the specific positions of FAU zeolite structure can be achieved upon the removal of organic ligands by calcination. ${ }^{[28]}$ The full retention of the framework structure of FAU zeolites and location of incorporated metal ions within the M@FAU zeolites have been confirmed by Rietveld refinements of high-resolution synchrotron X-ray powder diffraction. ${ }^{[28]}$ Similar approaches based upon a (3mercaptopropyl)trimethoxysiane ligand have been reported to deliver metal sites to specific locations in various zeolites to fabricate functional catalysts. ${ }^{[29]}$ The phase purity and porosity of desolvated M@FAU materials are confirmed by powder X-ray diffraction data and $\mathrm{Ar}$ adsorption isotherms, respectively (Supporting Information, Figure S1 and S2).

Analysis of gas adsorption and separation properties. Adsorption isotherms of $\mathrm{C}_{2} \mathrm{H}_{2}$ and $\mathrm{CO}_{2}$ on M@FAU ( $\mathrm{M}=\mathrm{Ni}, \mathrm{Cu}$, $\mathrm{Zn}$, Figure 1a, Supporting Information, Figure S3 and S4) and the parent Na-FAU zeolites (Figure 1b) were collected at $298 \mathrm{~K}$. All samples exhibited comparable adsorption capacity for $\mathrm{C}_{2} \mathrm{H}_{2}$ and $\mathrm{CO}_{2}$ at 1.0 bar, e.g., 3.55 and $3.88 \mathrm{mmol} \mathrm{g}^{-1}$, respectively, for $\mathrm{Cu} @ F A U$. The uptakes of $\mathrm{C}_{2} \mathrm{H}_{2}$ and $\mathrm{CO}_{2}$ of M@FAU samples are slightly lower than that of the pristine Na-FAU zeolite (4.63 and $5.32 \mathrm{mmol} \mathrm{g}^{-1}$, respectively) due to the reduction of BET surface area on incorporation of the metal sites (Supporting Information, Figure S2 and Table S2). It is worth noting that typical contents of $\mathrm{C}_{2} \mathrm{H}_{2}$ and $\mathrm{CO}_{2}$ in the cracking stream for the production of $\mathrm{C}_{2} \mathrm{H}_{2}$ are $7.5-8.8 \%$ and $3.2-3.5 \%$, respectively, ${ }^{[1]}$ and importantly, these decorated zeolites show significantly higher adsorption of $\mathrm{C}_{2} \mathrm{H}_{2}$ than $\mathrm{CO}_{2}$ under the corresponding partial pressures (e.g., 2.50 and $1.32 \mathrm{mmol} \mathrm{g}^{-1}$, respectively, for Cu@FAU at 0.07 and 0.04 bar; Supporting Information, Figure S5 and S6), affording great promise to explore their performance in the separation of $\mathrm{C}_{2} \mathrm{H}_{2} / \mathrm{CO}_{2}$. Although ideal adsorbed solution theory (IAST) is widely employed to evaluate the adsorption selectivity for various materials, ${ }^{[30]}$ the assumption of this theory is not valid in this case due to the presence of chemoselective adsorption of one component in the competitive adsorption (see below) and we therefore determined directly the selectivity of $\mathrm{C}_{2} \mathrm{H}_{2} / \mathrm{CO}_{2}$ separation by column breakthrough experiments.
Breakthrough separations of the mixture of $\mathrm{C}_{2} \mathrm{H}_{2} / \mathrm{CO}_{2} / \mathrm{He}$ (10/5/85; v/v/v) by M@FAU (Figure 1c, Supporting Information, Figure S7 and S8) and Na-FAU (Figure 1d) were conducted at $298 \mathrm{~K}$. The dynamic adsorption capacities of $\mathrm{C}_{2} \mathrm{H}_{2}$ for $\mathrm{Cu} @ \mathrm{FAU}$, $\mathrm{Ni@FAU,} \mathrm{Zn@FAU} \mathrm{and} \mathrm{Na-FAU} \mathrm{were} \mathrm{measured} \mathrm{as} \mathrm{2.29,} \mathrm{2.23,}$ 1.68 and $2.05 \mathrm{mmol} \mathrm{g}^{-1}$, respectively, and the dynamic selectivities of $\mathrm{C}_{2} \mathrm{H}_{2} / \mathrm{CO}_{2}$ are $1.71,1.62,1.41$ and 1.63 , respectively. The separation performance of Cu@FAU zeolite is comparable to that of the leading sorbent materials, such as FJU-90a, ${ }^{[10]}$ NKMOF-1-Ni, ${ }^{[14]} \mathrm{HOF}-3 \mathrm{a},{ }^{[17]} \mathrm{JCM}-1^{[18]}$ and SNNU$45,{ }^{[19]}$ but the selectivity is lower than that of the best-behaving MOFs incorporating narrow pores or open metal sites, namely UTSA-300a, ${ }^{[2]}$ UTSA-74a, ${ }^{[12]}$ SIFSIX-3-Ni, ${ }^{[15]}$ and TIFSIX-2-Cu-

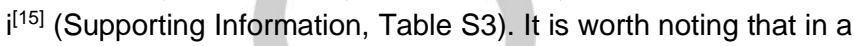
breakthrough experiment where co-adsorption occurs as observed in most reported studies, upon regeneration of the saturated sorbent, pure component gas cannot be obtained directly. For example, although Cu@FAU exhibits a decent dynamic selectivity of $\mathrm{C}_{2} \mathrm{H}_{2} / \mathrm{CO}_{2}$, the purity of $\mathrm{C}_{2} \mathrm{H}_{2}$ can only reach $\sim 80 \%$ upon desorption of he sorbent bed, restricting its practical applications (Figure 1c). a

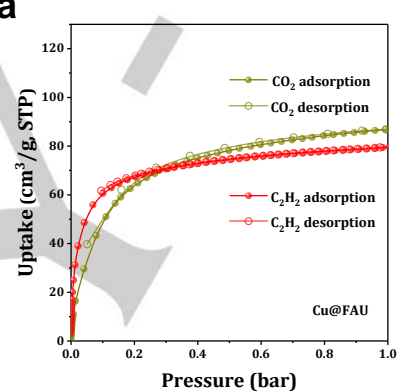

C

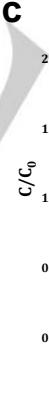

b

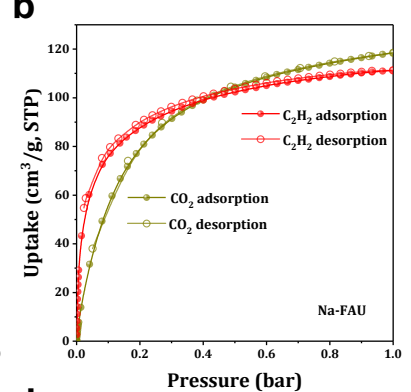

d

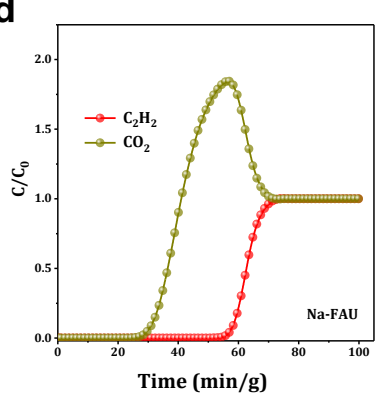

e

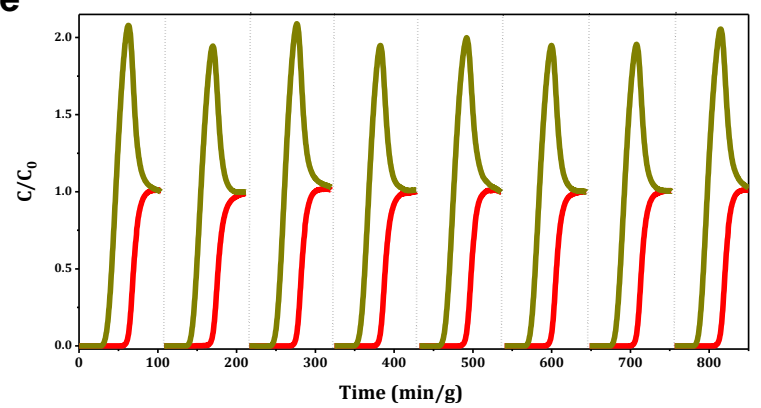

Figure 1. View of the adsorption and separation data of Cu@FAU and NaFAU. Data for other zeolite materials are shown in the Supporting Information. Adsorption isotherms of $\mathrm{C}_{2} \mathrm{H}_{2}$ and $\mathrm{CO}_{2}$ of $\mathrm{Cu} @ F A U(\mathbf{a})$ and $\mathrm{Na}-\mathrm{FAU}(\mathbf{b})$ at 298 $\mathrm{K}$; Column breakthrough curves of the mixture of $\mathrm{C}_{2} \mathrm{H}_{2} / \mathrm{CO}_{2} / \mathrm{He}$ at $298 \mathrm{~K}$ and 1 bar (10/5/85, v/v/v; total gas flow: $8.0 \mathrm{~mL} \mathrm{~min}^{-1}$, sample weight: $\left.0.5 \mathrm{~g}\right)$ over a fixed-bed packed with Cu@FAU (c) and Na-FAU (d). (e) The recyclability of $\mathrm{Cu}$ @FAU for the separation of $\mathrm{C}_{2} \mathrm{H}_{2} / \mathrm{CO}_{2}$ over eight cycles $\left(\mathrm{C}_{2} \mathrm{H}_{2}\right.$ : red; $\mathrm{CO}_{2}$ : dark yellow). The saturated sorbent was regenerated by heating at $473 \mathrm{~K}$ in a flow of $\mathrm{Ar}$ for 20 minutes between cycles. 
Establishment of an adsorption-purging-desorption system. To seek potential solutions, we further investigate the adsorption affinity between these two gas molecules and the sorbent. The isosteric heats of adsorption $\left(Q_{s t}\right)$ of $\mathrm{C}_{2} \mathrm{H}_{2}$ and $\mathrm{CO}_{2}$ within these zeolites have been determined by differential scanning calorimetry (DSC) measurements (Supporting Information, Figure S9-S16). ${ }^{[31,32]} \mathrm{Na}-\mathrm{FAU}$ exhibits similar $Q_{s t}$ values for the uptakes of $\mathrm{C}_{2} \mathrm{H}_{2}$ and $\mathrm{CO}_{2}$ (24.9 and $25.9 \mathrm{~kJ} \mathrm{~mol}^{-1}$, respectively). In contrast, the $Q_{s t}$ of $\mathrm{C}_{2} \mathrm{H}_{2}$ adsorption in Cu@FAU is almost twice that of $\mathrm{CO}_{2}\left(50.0\right.$ and $28.2 \mathrm{~kJ} \mathrm{~mol}^{-1}$, respectively), indicating the significantly stronger binding affinity of $\mathrm{C}_{2} \mathrm{H}_{2}$ than $\mathrm{CO}_{2}$ in $\mathrm{Cu} @ \mathrm{FAU}$. Thus, desorption of $\mathrm{CO}_{2}$ from $\mathrm{Cu@FAU}$ occurs under milder conditions than that would require for the desorption of $\mathrm{C}_{2} \mathrm{H}_{2}$, affording a valid opportunity to increase the concentration of $\mathrm{C}_{2} \mathrm{H}_{2}$ within $\mathrm{Cu} @ \mathrm{FAU}$ by desorbing $\mathrm{CO}_{2}$ at a mild condition, under which $\mathrm{C}_{2} \mathrm{H}_{2}$ can be largely retained in the pores.

To validate this hypothesis, temperature-programmed desorption (TPD) experiments were conducted. In a typical experiment, the zeolite sample was firstly dosed with the gas mixture of $\mathrm{C}_{2} \mathrm{H}_{2} / \mathrm{CO}_{2}(\mathrm{v} / \mathrm{v}=2 / 1)$ at $298 \mathrm{~K}$ and the effect of selective desorption by purging the saturated sample with a flow of $\mathrm{Ar}$ at $298 \mathrm{~K}$ was investigated. The TPD profiles of $\mathrm{CO}_{2}(\mathrm{~m} / \mathrm{z}=$ 44) and $\mathrm{C}_{2} \mathrm{H}_{2}(\mathrm{~m} / \mathrm{z}=26)$ were recorded at a heating rate of $10 \mathrm{~K}$ $\mathrm{min}^{-1}$ from 298 to $473 \mathrm{~K}$ under a flow of Ar. The comparison of the TPD profiles of the purged and unpurged Cu@FAU samples (Figure $2 \mathrm{c}, \mathrm{d}$ ) shows that the majority (>95\%) of adsorbed $\mathrm{CO}_{2}$ molecules were desorbed upon purging, while only $34 \%$ of the adsorbed $\mathrm{C}_{2} \mathrm{H}_{2}$ molecules were desorbed at the same time (Figure 2a, b). Importantly, Cu@FAU retains the highest amount of acetylene (1.51 mmol g-1) compared with Ni@FAU, Zn@FAU and $\mathrm{Na}-\mathrm{FAU}\left(0.75,0.27\right.$ and $0.55 \mathrm{mmol} \mathrm{g}^{-1}$, respectively) after this purging process. This suggests that the proportion of $\mathrm{C}_{2} \mathrm{H}_{2}$ in the adsorbed phase within $\mathrm{Cu@FAU} \mathrm{is} \mathrm{significantly} \mathrm{increased}$ after the selective desorption and high-purity $\mathrm{C}_{2} \mathrm{H}_{2}$ could be obtained on the complete desorption. Indeed, the concentrations of acetylene in the final desorbed gas streams are 97.8, 90.2, 95.4 and 94.4 \% for Cu@FAU, Zn@FAU, Ni@FAU, and Na-FAU, respectively. Thus, the three-stage process based upon "adsorption-purging-desorption" has effectively increased the separation factor $(\alpha)$ of $\mathrm{C}_{2} \mathrm{H}_{2} / \mathrm{CO}_{2}$ from 1.71 to 22.2 for $\mathrm{Cu} @ \mathrm{FAU}$, which is $\sim 3$ times of Na-FAU (from 1.63 to 8.40; Figure 2e), demonstrating the key role of confined $\mathrm{Cu}$ (II) sites in enhancing the separation performance of FAU zeolites. It worth noting that the introduction of $\mathrm{Cu}$ (II) sites in FAU zeolites via post-synthesis ion-exchange (denoted as Cu-FAU) or wet impregnation (denoted as CuO/FAU) are poorly effective to promote the separation of $\mathrm{C}_{2} \mathrm{H}_{2} / \mathrm{CO}_{2}$ (Supporting Information, Figure S23-S26) because the location of $\mathrm{Cu}$ (II) sites in $\mathrm{Cu}-\mathrm{FAU}$ and CuO/FAU can undergo dynamic changes under different conditions and is often poorly accessible by the guest molecules. ${ }^{[33,34]}$ Thus, this result demonstrates the importance of location of confined $\mathrm{Cu}$ (II) sites introduced by the direct hydrothermal synthesis.

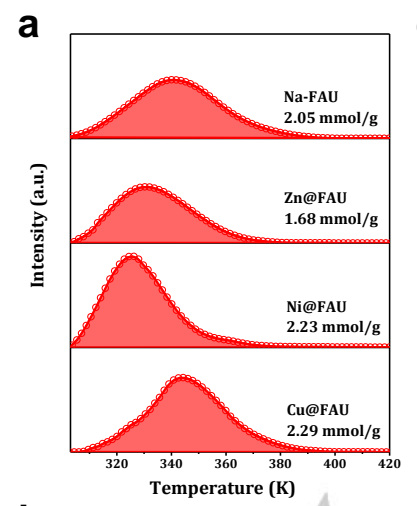

b

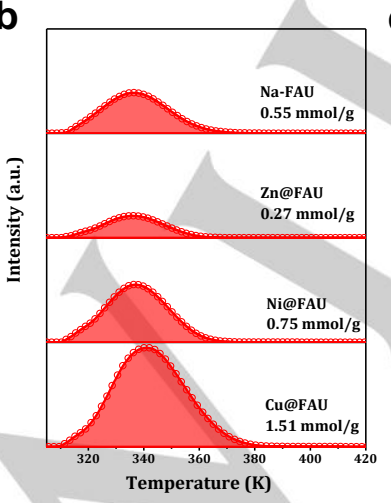

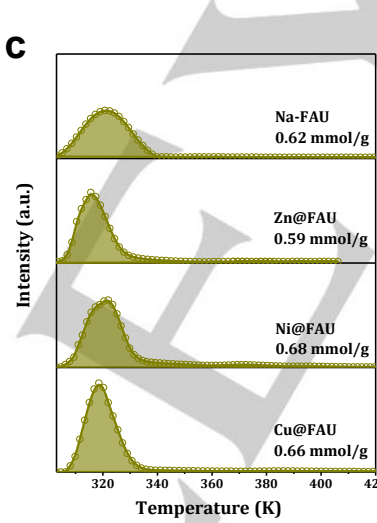

d

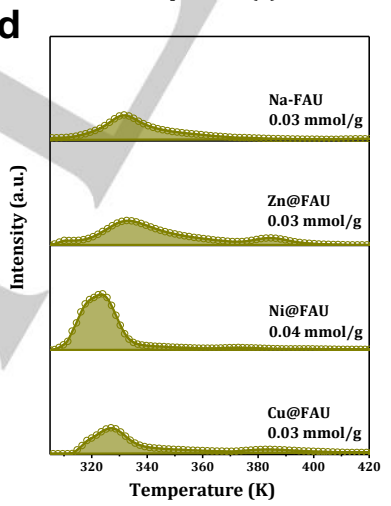

e
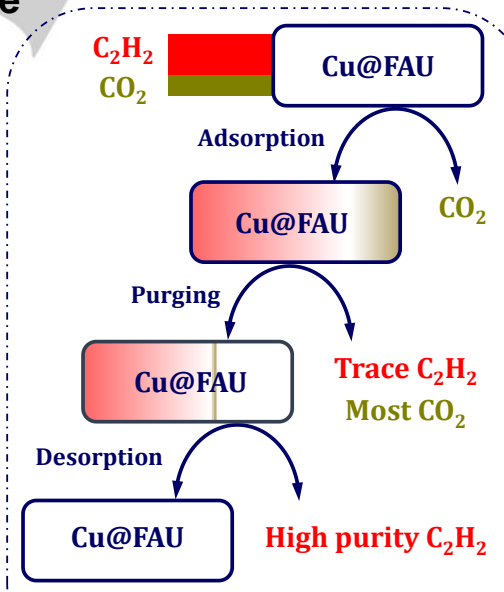

$\ddots \quad$ Single Unit Separation

Na-FAU $\alpha=8.4$

Ni@FAU $\alpha=10.4$

Cu@FAU $\alpha=22.2$

Zn@FAU $\alpha=4.6$

Figure 2. Views of the TPD profiles of gas-loaded M@FAU (M=Cu, $\mathrm{Zn}, \mathrm{Ni}$ ) and Na-FAU samples as function of temperature. TPD profiles of adsorbed $\mathrm{C}_{2} \mathrm{H}_{2}$ released from the unpurged samples (a) and from samples after purging by $\mathrm{Ar}$ at $298 \mathrm{~K}(\mathbf{b})$; TPD profiles of adsorbed $\mathrm{CO}_{2}$ released from the unpurged samples (c) and from samples after purging by $\mathrm{Ar}$ at $298 \mathrm{~K}$ (d). (e) A schematic view of the designed adsorption-purging-desorption process for the recovery of high-purity $\mathrm{C}_{2} \mathrm{H}_{2}$ via separation of the mixture of $\mathrm{C}_{2} \mathrm{H}_{2} / \mathrm{CO}_{2}$ by decorated $\mathrm{FAU}$ zeolites.

The effect of operating conditions on the separation of $\mathrm{C}_{2} \mathrm{H}_{2} / \mathrm{CO}_{2}$ was investigated. The adsorption capacity of $\mathrm{C}_{2} \mathrm{H}_{2}$ for $\mathrm{Cu}$ @FAU decreases slightly with increasing flow rate of gas mixtures from 15 to $20 \mathrm{~mL} \mathrm{~min}^{-1}$ or with rising temperature from
298 to $323 \mathrm{~K}$ (Supporting Information, Figure S27-S30). Upon dilution of $\mathrm{C}_{2} \mathrm{H}_{2}$ and $\mathrm{CO}_{2}$ by a factor of 5 in the gas stream (i.e., $10 \%$ to $2 \%$ and $5 \%$ to $1 \%$, respectively), Na-FAU exhibited a decrease in the dynamic adsorption capacity of $\mathrm{C}_{2} \mathrm{H}_{2}$ (from 2.05 
to $1.24 \mathrm{mmol} \mathrm{g}^{-1}$ ) but no change in the selectivity (Supporting Information, Figure S31), whereas for Cu@FAU, although the former decreased from 2.29 to $1.68 \mathrm{mmol} \mathrm{g}^{-1}$, the selectivity of $\mathrm{C}_{2} \mathrm{H}_{2}$ increased from 1.71 to 2.35 (Supporting Information, Figure S32). Endowed with the high structural stability and operational flexibility, Cu@FAU zeolites can function in a modular manner. For example, with a single separation unit based upon Cu@FAU, $1.51 \mathrm{mmol} \mathrm{g}^{-1} \mathrm{C}_{2} \mathrm{H}_{2}$ with the purity of $97.8 \%$ can be obtained from an industrially relevant mixture of $\mathrm{C}_{2} \mathrm{H}_{2} / \mathrm{CO}_{2}(\mathrm{v} / \mathrm{v}=2 / 1)$, and $\mathrm{C}_{2} \mathrm{H}_{2}$ can be produced with even higher purity by using multiple separation units (Figure 2e). For example, an acetylene stream with purity $>99 \%$ can be obtained with use of a second unit, demonstrating its promising potential in practical applications.

Determination of binding sites of $\mathrm{C}_{2} \mathrm{D}_{2}$ and $\mathrm{CO}_{2}$ within $\mathrm{Cu} @ F A U$. The binding sites of adsorbed $\mathrm{C}_{2} \mathrm{D}_{2}$ and $\mathrm{CO}_{2}$ molecules within the pore of $\mathrm{Cu}$ @FAU were determined by in situ NPD. Fourier difference map analysis of the desolvated

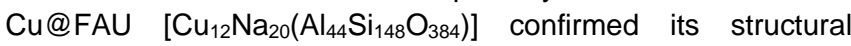
integrity and the absence of residual nuclear density in the supercage. $\mathrm{Cu}(\mathrm{II})$ was found to be stabilised by framework oxygen centres of the six-membered ring of the sodalite cage. Upon gas loading, variations in Bragg peak intensities were observed, and the binding domains of gases were successfully interpreted by Fourier difference map analysis and Rietveld refinements (Figure 3). In $\left[\mathrm{Cu}_{12} \mathrm{Na}_{20}\left(\mathrm{Al}_{44} \mathrm{Si}_{148} \mathrm{O}_{384}\right)\right] \cdot\left(\mathrm{C}_{2} \mathrm{D}_{2}\right)_{30}$, two distinct $\mathrm{C}_{2} \mathrm{D}_{2}$ sites were identified with Site I showing strong interactions with $\mathrm{Cu}(\mathrm{II})$ centres and accounting for $63 \%$ of adsorbed $\mathrm{C}_{2} \mathrm{D}_{2}$ molecules. Unlike classic side-on interactions between transition metal and $\mathrm{C} \equiv \mathrm{C}$ bond in cation-acetylene complexation $^{[35]}$ and that observed in $\mathrm{C}_{2} \mathrm{D}_{2}$-loaded $\mathrm{Ni@FAU}{ }^{[28]}$, $\mathrm{C}_{2} \mathrm{D}_{2}(\mathrm{I})$ is noticeably tilted with $\mathrm{C}$... Cu distances being 2.49 and $3.35 \AA$, and $\angle \mathrm{C} \equiv \mathrm{C} \cdots \mathrm{Cu}$ of $126.0^{\circ}$ (Figure 3a-c, Supporting Information, Figure S33). This is originated from the presence of additional strong hydrogen bonds between adsorbed $\mathrm{C}_{2} \mathrm{D}_{2}$ molecules and the oxygen centres of the framework $\left(D_{\mathrm{C} 2 \mathrm{D} 2} \cdots\right.$ $\mathrm{O}_{\text {framework }}=1.89 \AA$ A). In situ X-ray photoelectron spectroscopy confirmed the retention of the a divalent oxidation state of $\mathrm{Cu}(\mathrm{II})$ sites on acetylene binding (Supporting Information, Figure S34). $\mathrm{C}_{2} \mathrm{D}_{2}$ (II) locates away from $\mathrm{Cu}(\mathrm{II})$ centres and is solely stabilised by weak host-guest hydrogen bond $\left(\mathrm{D}_{\mathrm{C} 2 \mathrm{D} 2} \cdots \mathrm{O}_{\text {tramework }}=2.64 \AA\right.$ ). $\mathrm{C}_{2} \mathrm{D}_{2}$ (II) accounts for $37 \%$ of the total adsorbed $\mathrm{C}_{2} \mathrm{D}_{2}$ molecules, in excellent agreement with the loss of $\mathrm{C}_{2} \mathrm{H}_{2}$ uptake (34\%) on purging observed in the adsorption-purging process. Thus, this confirms that the combination of $\mathrm{Cu}$ (II) sites and strong hydrogen bonds results in the retention of $\mathrm{C}_{2} \mathrm{H}_{2}$ in $\mathrm{Cu} @ F A U$ upon purging. Interestingly, the result is distinct to that observed $\mathrm{C}_{2} \mathrm{D}_{2}$-loaded Ni@FAU ${ }^{[28]}$, where all $\mathrm{C}_{2} \mathrm{D}_{2}$ molecules were located at a single site showing a side-on binding to the $\mathrm{Ni}$ (II) sites.

In comparison, only one binding site was found for adsorbed $\mathrm{CO}_{2}$ molecules in $\left[\mathrm{Cu}_{12} \mathrm{Na}_{20}\left(\mathrm{Al}_{44} \mathrm{Si}_{148} \mathrm{O}_{384}\right)\right] \cdot\left(\mathrm{CO}_{2}\right)_{18}$, which exhibits notably weaker host-guest interactions $\left(\mathrm{C}_{\mathrm{CO} 2} \cdots \mathrm{O}_{\text {framework }}=3.08 \AA \AA \quad \mathrm{O}_{\mathrm{CO} 2} \cdots \mathrm{Cu}=3.18 \AA\right.$; Figure $3 \mathrm{~d}-\mathrm{f}$, Supporting Information, Figure S35). The above studies showed that coordinatively unsaturated $\mathrm{Cu}$ (II) sites confined in Cu@FAU provided unique binding sites with significantly stronger adsorption affinity to $\mathrm{C}_{2} \mathrm{H}_{2}$ than to $\mathrm{CO}_{2}$. This leads to its superior performance in the separation of $\mathrm{C}_{2} \mathrm{H}_{2} / \mathrm{CO}_{2}$ and the recovery of high-purity $\mathrm{C}_{2} \mathrm{H}_{2}$ from the designed adsorption-purgingdesorption process. a

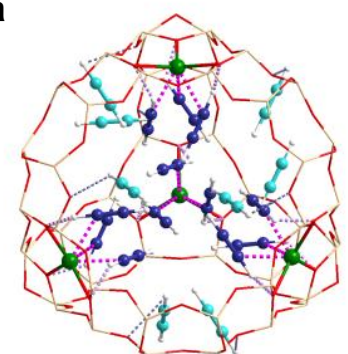

b

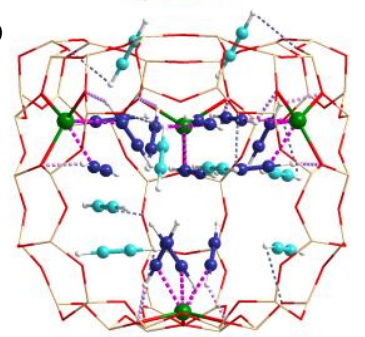

C

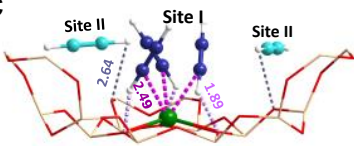

d

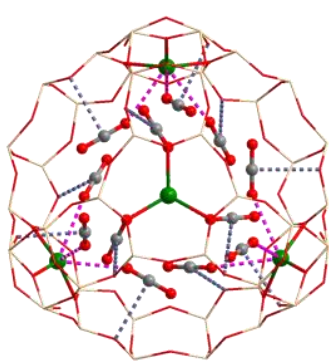

e

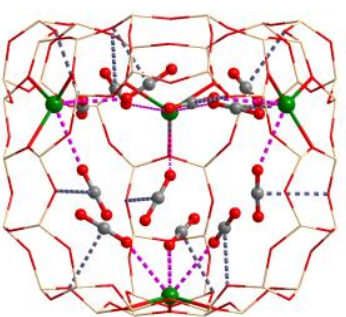

f

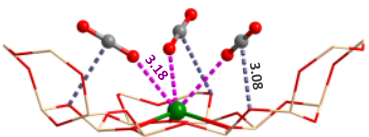

Figure 3. Views of crystal structures of the Cu@FAU zeolite as a function of gas loading. All structures were derived from Rietveld refinements of neutron powder diffraction (NPD) data at $10 \mathrm{~K}$ [Si/Al: yellow; O: red; Ni: green. C: grey; D: white; for clarity, $\mathrm{C}_{2} \mathrm{D}_{2}(\mathbf{I})$ and $\mathrm{C}_{2} \mathrm{D}_{2}$ (II) are highlighted in dark and light blue, respectively]. The host-guest interactions are highlighted in dash lines and the estimated standard deviation (e.s.d.) values for binding distances are typically within $0.01-0.1 \AA$. Views of binding sites for adsorbed gas molecules in $\left[\mathrm{Cu}_{12} \mathrm{Na}_{20}\left(\mathrm{Al}_{44} \mathrm{Si}_{148} \mathrm{O}_{384}\right)\right] \cdot\left(\mathrm{C}_{2} \mathrm{D}_{2}\right)_{30} \quad$ (a) and $\left[\mathrm{Cu}_{12} \mathrm{Na}_{20}\left(\mathrm{Al}_{44} \mathrm{Si}_{148} \mathrm{O}_{384}\right)\right] \cdot\left(\mathrm{CO}_{2}\right)_{18}$ (d) along the $(1,1,1)$ axis; packing of adsorbed $\mathrm{C}_{2} \mathrm{D}_{2}$ (b) and $\mathrm{CO}_{2}(\mathbf{e})$ molecules in the supercage; views of the hostguest binding interactions between $\mathrm{C}_{2} \mathrm{D}_{2}(\mathbf{c})$ or $\mathrm{CO}_{2}(\mathbf{f})$ and the $\mathrm{Cu}(\mathrm{II})$ site and the framework oxygen centres.

Analysis of host-guest binding dynamics. The host-guest binding dynamics has been studied by in situ INS (Figure 4). Translational and librational modes of $\mathrm{C}_{2} \mathrm{H}_{2}$ contribute to the low energy region of the spectra $(<30 \mathrm{emV})$. With both low $(1.0$ $\mathrm{C}_{2} \mathrm{H}_{2} / \mathrm{Cu}$; peaks labelled as a-f) and high $\left(3.0 \mathrm{C}_{2} \mathrm{H}_{2} / \mathrm{Cu}\right.$; peaks labelled as a'-f') loading of $\mathrm{C}_{2} \mathrm{H}_{2}$ in $\mathrm{Cu} @ \mathrm{FAU}$, two peaks were observed below $8 \mathrm{meV}$, which correlate with the distinct two $\mathrm{C}_{2} \mathrm{H}_{2}$ sites identified by NPD. Peak a and a' occurring at lower energy $(3.5 \mathrm{meV})$ are assigned to the translational/rotational motion of $\mathrm{C}_{2} \mathrm{H}_{2}$ at Site II, which only interacts weakly with the framework oxygen centres. Peak $\mathbf{b}$ and $\mathbf{b}$ ' at higher energy (5.7 and $6.1 \mathrm{meV}$, respectively) are assigned to the motion of $\mathrm{C}_{2} \mathrm{H}_{2}$ at Site I within the plane perpendicular to the $\mathrm{Cu}$ (II)-gas axis. The fact that the $\mathrm{C}_{2} \mathrm{H}_{2}$ molecules are more isolated and restricted in anisotropic environment upon adsorption in Cu@FAU results in such distinct INS features at low energy region, whereas coupled and dispersed modes are observed in solid state where $\mathrm{C}_{2} \mathrm{H}_{2}$ interacts with adjacent $\mathrm{C}_{2} \mathrm{H}_{2}$ molecules in all three dimensions. INS features $\mathbf{c}$ and $\mathbf{c}^{\prime}(8-17 \mathrm{meV})$ are assigned to the rotational or twisting modes of adsorbed $\mathrm{C}_{2} \mathrm{H}_{2}$ molecules, and the broad peaks $\mathbf{d}$ and d' $(20 \mathrm{meV})$ are due to motions of the gas molecules' moving toward or away from the binding sites on the framework.

At the high energy region, peaks $\mathbf{e}$ and $\mathbf{e}^{\prime}$ are assigned to the trans- $\mathrm{C}-\mathrm{H}$ bending mode of the adsorbed $\mathrm{C}_{2} \mathrm{H}_{2}$. Deconvolution of peak e shows two contributing peaks centred at 79.3 and $82.5 \mathrm{meV}$ with a ratio of $0.22: 1$ (Supporting Information, Figure S36, which correspond to adsorbed $\mathrm{C}_{2} \mathrm{H}_{2}$ 
molecules at Site II and I, respectively. Similarly, on additional loading of $\mathrm{C}_{2} \mathrm{H}_{2}$, deconvolution of peak e' yields two individual peaks (78.9 and $82.0 \mathrm{meV}$ ) and the ratio of peak areas increased to $0.29: 1$, in good agreement with the NPD and dynamic adsorption results. This result is in sharp comparison to that observed in $\mathrm{C}_{2} \mathrm{H}_{2}$-loaded $\mathrm{Ni@FAU,} \mathrm{where} \mathrm{a} \mathrm{single}$ adsorption site was observed. ${ }^{[28]}$ Peak $\mathbf{f}$ and ' ${ }^{\prime}$ at $\sim 99 \mathrm{meV}$ are assigned to the cis- $\mathrm{C}-\mathrm{H}$ bending mode of the adsorbed $\mathrm{C}_{2} \mathrm{H}_{2}$ molecule. The apparent blue shift of these peaks comparing to that of solid $\mathrm{C}_{2} \mathrm{H}_{2}(97 \mathrm{meV})$ indicates that these modes are heavily hindered upon binding to the $\mathrm{Cu}$ (II) sites within Cu@FAU. Since both $\mathrm{CO}_{2}$ and $\mathrm{Cu@FAU} \mathrm{scatter} \mathrm{thermal} \mathrm{neutrons} \mathrm{weakly}$ (compared with $\mathrm{C}_{2} \mathrm{H}_{2}$ ), direct observation of adsorbed $\mathrm{CO}_{2}$ molecules with INS is challenging. Attempt has been made but no strong and convincing feature was observed in the difference spectrum, consistent with the weak Cu@FAU $\cdots \mathrm{CO}_{2}$ interactions. The host-guest binding mechanism of $\mathrm{C}_{2} \mathrm{H}_{2}$ and $\mathrm{CO}_{2}$ within Cu@FAU has also been investigated by in situ FTIR spectroscopy, which confirmed the presence of stronger binding of $\mathrm{C}_{2} \mathrm{H}_{2}$ than $\mathrm{CO}_{2}$, and under dynamic and competitive adsorption conditions, adsorbed $\mathrm{CO}_{2}$ molecules can be readily displaced by $\mathrm{C}_{2} \mathrm{H}_{2}$ molecules, consistent with the breakthrough, NPD and INS analysis (Supporting Information, Figure S37).

a

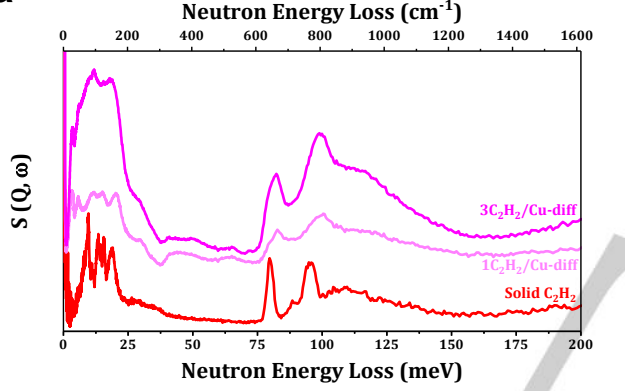

b

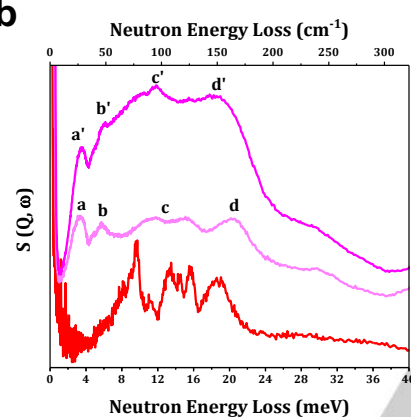

C

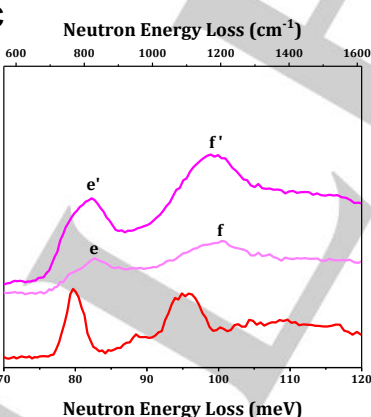

Figure 4. Inelastic neutron scattering (INS) spectra of Cu@FAU as a function of $\mathrm{C}_{2} \mathrm{H}_{2}$ loading. Diff-spectra were obtained by subtracting the spectrum of bare Cu@FAU from the spectra of $\mathrm{C}_{2} \mathrm{H}_{2}$-loaded Cu@FAU (a). (b) and (c) are the enlarged spectrum of (a), showing detailed features at the low and high energy regions, respectively.

\section{Conclusion}

The adsorptive separation of $\mathrm{C}_{2} \mathrm{H}_{2} / \mathrm{CO}_{2}$ based upon porous adsorbents represents a promising energy-efficient strategy to produce high-quality $\mathrm{C}_{2} \mathrm{H}_{2}$ for industrial applications. By confining coordinatively unsaturated $\mathrm{Cu}$ (II) sites in FAU zeolites, Cu@FAU has shown an excellent performance in the separation of $\mathrm{C}_{2} \mathrm{H}_{2} / \mathrm{CO}_{2}$, representing the first example of such in zeolite materials. Cu@FAU demonstrates high dynamic uptake of $\mathrm{C}_{2} \mathrm{H}_{2}$ of $2.29 \mathrm{mmol} \mathrm{g}^{-1}$ and dynamic selectivity of 1.71 under ambient conditions. The excellent stability of Cu@FAU in the processes was demonstrated by 8 cycles of binary breakthrough experiments, where Cu@FAU can be fully regenerated with complete retention of the productivity of $\mathrm{C}_{2} \mathrm{H}_{2}$ (Figure $1 \mathrm{e}$ and Supporting Information, Figure S38). Analyses combining in situ NPD, INS, and adsorption thermodynamic parameters afford full understanding on the underlying host-guest chemistry that drives the separation process. The confined $\mathrm{Cu}(\mathrm{II})$ ions play an important role in the selective binding and retention of $\mathrm{C}_{2} \mathrm{H}_{2}$, which is further supplemented by strong host-guest hydrogen bonds, whereas $\mathrm{CO}_{2}$ displays poor interaction to the zeolite interior and thus is readily displaced by $\mathrm{C}_{2} \mathrm{H}_{2}$ and eluted from the fixed-bed under flow conditions. By virtue of the different adsorption behaviour and mechanisms of these two molecules, a new adsorption-purging-desorption strategy is established for the recovery of $\mathrm{C}_{2} \mathrm{H}_{2}$ with high purity. Figure 5 shows a direct comparison between the dynamic separation factor/selectivity of mixtures of $\mathrm{C}_{2} \mathrm{H}_{2} / \mathrm{CO}_{2}$ and dynamic uptake of $\mathrm{C}_{2} \mathrm{H}_{2}$ in all leading sorbent materials. In a single separation unit, high effective dynamic uptake of $\mathrm{C}_{2} \mathrm{H}_{2}$ of $1.51 \mathrm{mmol} \mathrm{g}^{-1}$ and an unprecedented separation factor of 22.2 have been achieved on Cu@FAU, yielding the $\mathrm{C}_{2} \mathrm{H}_{2}$ stream with a high purity of $97.8 \%$. $\mathrm{C}_{2} \mathrm{H}_{2}$ with a purity of $>99 \%$ could be obtained by using a secondary separation unit in a modular manner since the large-scale synthesis of Cu@FAU can be readily achieved. This study highlights the versatility of decorated zeolite materials and their great potential in challenging gas separations in industry.

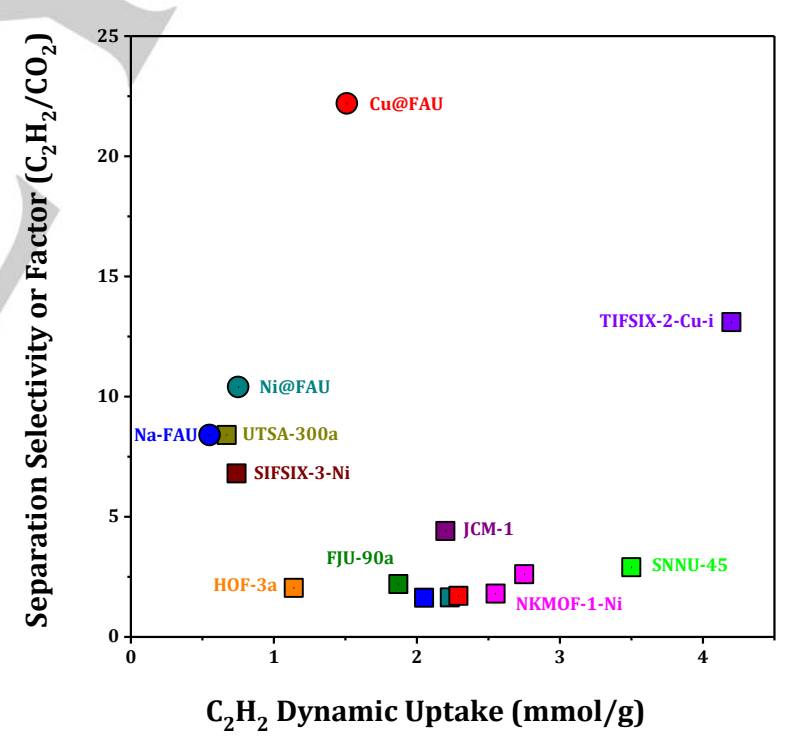

Figure 5. Comparison of the dynamic separation factor/selectivity of the mixture of $\mathrm{C}_{2} \mathrm{H}_{2} / \mathrm{CO}_{2}$ against the dynamic uptake of $\mathrm{C}_{2} \mathrm{H}_{2}$ under ambient conditions for state-of-the-art sorbent materials. The three-stage process based upon adsorption-purging-desorption (data shown in circle) has significantly increased the effective separation factors. Table S3 (Supporting Information) lists all numerical data of this graph.

\section{Acknowledgements}

We acknowledge the National Natural Science Fund of China (22025203), the Municipal Natural Science Fund of Tianjin (18JCJQJC47400), the Royal Society and the University of Manchester for funding. SW and SY thank the Royal Society for 
a Newton Advanced Fellowship. We thank STFC/ISIS Facility for the access to Beamline WISH. Inelastic neutron scattering experiments were conducted at the VISION beamline at ORNL's Spallation Neutron Source, which is supported by the Scientific User Facilities Division, Office of Basic Energy Sciences (BES), U.S. Department of Energy (DOE), under Contract No. DEAC0500OR22725 with UT Battelle, LLC. JL thanks China Scholarship Council for funding.

Keywords: zeolite $\cdot$ gas separation $\cdot$ acetylene $\cdot$ neutron diffraction $\cdot$ neutron scattering

[1] Pässler, P.; Hefner, W.; Buckl, K.; Meinass, H.; Meiswinkel, A.; Wernicke H. J.; Ebersberg, G.; Müller, R.; Bässler, J.; Behringer, H., Acetylene, Wiley-VCH, Weinheim, 2000.

[2] R. B. Lin, L. Li, H. Wu, H. Arman, B. Li, R. G. Lin, W. Zhou, B. Chen, J. Am. Chem. Soc. 2017, 139, 8022-8028.

[3] C. R. Reid, K. M. Thomas, J. Phys. Chem. B 2001, 105, 10619-10629.

[4] J. R. Li, R. J. Kuppler, H. C. Zhou, Chem. Soc. Rev. 2009, 38, 14771504.

[5] J. Li, L. Jiang, S. Chen, A. Kirchon, B. Li, Y. Li, H. C. Zhou, J. Am. Chem. Soc. 2019, 141, 3807-3811.

[6] Z. Zhang, S. B. Peh, Y. Wang, C. Kang, W. Fan, D. Zhao, Angew. Chem. Int. Ed. 2020, 59, 1-7.

[7] Y. Wang, S. B. Peh, D. Zhao, Small 2019, 15, 1900058.

[8] C. R. Reid, K. M. Thomas, Langmuir 1999, 15, 3206-3218.

[9] B. L. Newalkar, N. V. Choudary, U. T. Turaga, R. P. Vijayalakshmi, P. Kumar, S. Komarneni, T. S. G. Bhat, Microporous Mesoporous Mater. 2003, 65, 267-276.

[10] Y. Ye, Z. Ma, R. B. Lin, R. Krishna, W. Zhou, Q. Lin, Z. Zhang, S. Xiang, B. Chen, J. Am. Chem. Soc. 2019, 141, 4130-4136.

[11] J. P. Zhang, X. M. Chen, J. Am. Chem. Soc. 2009, 131, 5516-5521.

[12] F. Luo, C. Yan, L. Dang, R. Krishna, W. Zhou, H. Wu, X. Dong, Y. Han, T. L. Hu, M. O'Keeffe, L. Wang, M. Luo, R. B. Lin, B. Chen, J. Am. Chem. Soc. 2016, 138, 5678-5684.

[13] M. L. Foo, R. Matsuda, Y. Hijikata, R. Krishna, H. Sato, S. Horike, A. Hori, J. Duan, Y. Sato, Y. Kubota, M. Takata, S. Kitagawa, J. Am. Chem. Soc. 2016, 138, 3022-3030.

[14] Y. L. Peng, T. Pham, P. Li, T. Wang, Y. Chen, K. J. Chen, K. A. Forrest, B. Space, P. Cheng, M. J. Zaworotko, Z. Zhang, Angew. Chem. Int. Ed. 2018, 57, 10971-10975.

[15] K. J. Chen, H. S. Scott, D. G. Madden, T. Pham, A. Kumar, A. Bajpai, M. Lusi, K. A. Forrest, B. Space, J. J. Perry, M. J. Zaworotko, Chem 2016, 1, 753-765.

[16] R. Eguchi, S. Uchida, N. Mizuno, Angew. Chem. Int. Ed. 2012, 51, 1635-1639.

[17] P. Li, Y. He, Y. Zhao, L. Weng, H. Wang, R. Krishna, H. Wu, W. Zhou, M. O'Keeffe, Y. Han, B. Chen, Angew. Chem. Int. Ed. 2015, 54, 574577.

[18] J. Lee, C. Y. Chuah, J. Kim, Y. Kim, N. Ko, Y. Seo, K. Kim, T. H. Bae, E. Lee, Angew. Chem. Int. Ed. 2018, 130, 7995-7999.

[19] Y. Li, Y. Wang, Y. Xue, H. Li, Q. Zhai, S. Li, Y. Jiang, M. Hu, X. Bu, Angew. Chem. Int. Ed. 2019, 131, 13724-13729.

[20] H. Wang, X. Dong, V. Colombo, Q. Wang, Y. Liu, W. Liu, X. L. Wang, X. Y. Huang, D. M. Proserpio, A. Sironi, Y. Han, J. Li, Adv. Mater. 2018, 30, 1805088.

[21] X. Wang, Z. Niu, A. M. Al-Enizi, A. Nafady, Y. Wu, B. Aguila, G. Verma, L. Wojtas, Y. S. Chen, Z. Li, S. Ma, J. Mater. Chem. A 2019, 7, 13585.

[22] H. Wang, Y. Liu, J. Li, Adv. Mater. 2020, 2002603, 1.

[23] Z. Niu, X. Cui, T. Pham, P. C. Lan, H. Xing, K. A. Forrest, L. Wojtas, B. Space, S. Ma, Angew. Chem. Int. Ed. 2019, 58, 10138-10141.

[24] W. Xu, B. Tu, Q. Liu, Y. Shu, C. C. Liang, C. S. Diercks, O. M. Yaghi, Y. B. Zhang, H. Deng, Q. Li, Nat. Rev. Mater. 2020, 5, 764-779.

[25] R. T. Yang, Gas Separation by Adsorption Processes, Butterworth Stoneham, 1987

[26] P. J. Bereciartua, Á. Cantín, A. Corma, J. L. Jordá, M. Palomino, F. Rey, S. Valencia, E. W. Corcoran, P. Kortunov, P. I. Ravikovitch, A. Burton,
C. Yoon, Y. Wang, C. Paur, J. Guzman, A. R. Bishop, G. L. Casty, Science 2017, 358, 1068-1071.

[27] D. W. Breck, W. G. Eversole, R. M. Milton, T. B. Reed, T. L. Thomas, J. Am. Chem. Soc. 1956, 78, 5963-5972.

[28] Y. Chai, X. Han, W. Li, S. Liu, S. Yao, C. Wang, W. Shi, I. Da-Silva, P. Manuel, Y. Cheng, L. D. Daemen, A. J. Ramirez-Cuesta, C. C. Tang, L. Jiang, S. Yang, N. Guan, Landong Li, Science 2020, 368, 1002-1006.

[29] M. Choi, Z. Wu, E. Iglesia, J. Am. Chem. Soc. 2010, 132, 9129-9137.

[30] A. L. Myers, J. M. Prausnitz, AlChE J. 1965, 11, 121-127.

[31] A. Cadiau, K. Adil, P. M. Bhatt, Y. Belmabkhout, M. Eddaoudi, Science 2016, 353, 137-140.

[32] P. M. Bhatt, Y. Belmabkhout, A. Cadiau, K. Adil, O. Shekhah, A. Shkurenko, L. J. Barbour, M. Eddaoudi, J. Am. Chem. Soc. 2016, 138 9301-9307.

[33] R. A. Schoonheydt, Catal. Rev. 1993, 35, 129-168.

[34] A. Delabie, K. Pierloot, M. H. Groothaert, R. A. Schoonheydt, L. G. Vanquickenborne, Eur. J. Inorg. Chem. 2002, 3, 515-530.

[35] J. H. Nelson, H. B. Jonassen, Coord. Chem. Rev. 1971, 6, 27-63. 


\section{Entry for the Table of Contents}

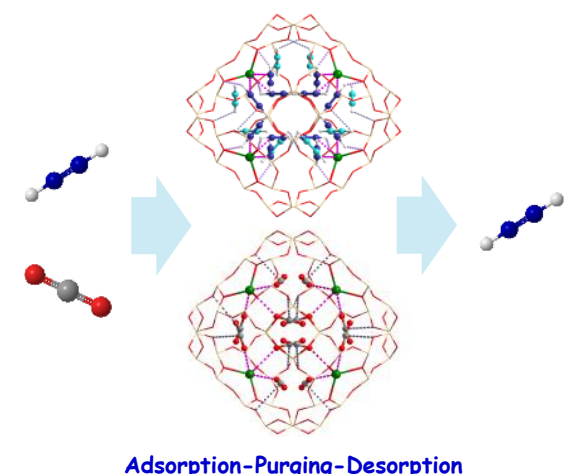

Adsorption-Purging-Desorption

A decorated zeolite material Cu@FAU exhibits highly selective adsorption of acetylene and thus efficient separation of acetylene and carbon dioxide, unlocking the potential of zeolite materials in challenging industrial separations. 